Joel Sobel ${ }^{1}$

\title{
What Makes Money Work?
}

\section{Comments on "The Guidance of an Enterprise Economy"}

\footnotetext{
${ }^{1}$ Department of Economics, University of California, San Diego, La Jolla, CA 92093, U.S.A., E-mail: jsobel@ucsd.edu. https://orcid.org/0000-0003-4699-9975.
}

DOI: 10.1515/ael-2017-0051

Review of "The Guidance of an Enterprise Economy", By M. Shubik and E. Smith. (Cambridge, Massachusetts: The MIT Press, 2016).

Table of Contents

1. Introduction

2. Moving beyond general equilibrium

3. From theory to applications

4. Economics and science

5. A missing link

6. How to read the book

Tribute to Martin Shubik

1. "Accounting and its Relationship to General Equilibrium Theory" by Martin Shubik, https: / /doi.org/10.1515/ael-2018-0054

2. "Martin Shubik's Curriculum Vitae" by Shyam Sunder, https://doi.org/10.1515/ael-2019-2047

3. “The Visible Hand" by Andrew W. Lo, https:/ /doi.org/10.1515/ael-2018-0012

4. “What Makes Money Work? Comments on “The Guidance of an Enterprise Economy"” by Joel Sobel, https://doi.org/10.1515/ael-2017-0051

5. "Institutions, Games and Economic Theory: Comments on the Guidance of an Enterprise Economy by Martin Shubik and Eric Smith, MIT Press 2016" by Douglas W. Diamond, https:/ / doi.org/10.1515/ael-2019-0047

6. "Equilibrium and System Analysis in Economic Dynamics. A Comment on the "Guidance of an Enterprise economy" by Martin Shubik and Eric Smith" by Yuri Biondi, https:/ / doi.org/10.1515/ael-2018-0027

\section{Introduction}

A few months ago, my return trip from a European conference involved changing planes in Washington D.C. The first flight went fine and I boarded the plane for the Washington - San Diego segment. One hour later, after being informed that there was a problem with the plane, I disembarked. Two hours later, the flight was cancelled. It took several more hours to negotiate an alternate route. The delays provided a perfect time to become angry with the airline, technology, and many other aspects of modern life. Somehow, these bitter emotions changed into awe. I arrived home twelve hours later than expected, more exhausted than usual, but otherwise in fine shape. I managed to travel half way across the world in about thirty hours. A complex machine failed. A complicated network of connections managed to find a replacement. Many details were unpleasant, but the final outcome was not too different from what I expected. I assume that 250 other displaced passengers had a similar experience (perhaps without the awe).

Joel Sobel is the corresponding author.

(c) 2019 Walter de Gruyter $\mathrm{CmbH}$, Berlin/Boston.

This content is free. 
Air travel is just an example of the extraordinarily complex processes that we take for granted. Shubik and Smith's book provides a multi-disciplinary foundation for the study of large-scale market interactions that is rich enough to generate insights into how systems work. The authors are aware that complex systems may fail and that the failures may lead to consequences far worse than a twelve-hour delay. They seek to describe ways in which imperfect people can create and govern complicated institutions well enough to avoid disastrous outcomes and secure good outcomes frequently.

\section{Moving beyond general equilibrium}

The starting point for the analysis is the theory of general equilibrium. A focus of mathematical economics in the 1950s, general-equilibrium theory is an elegant formulation of economic interaction. The theory provides a precise description of the interaction between goal-oriented agents producing and exchanging goods. The theory delivers three central results. The first result is an existence theorem that shows the coherence of the model and captures the intuition that it is possible to find prices that equate supply to demand. The other results are the two fundamental theorems of welfare economics: conditions under which an equilibrium is Pareto efficient and conditions under which any Pareto-efficient allocation can be viewed as an equilibrium (with appropriate initial conditions). Thanks to deep insights from the founders of this theory, one could view the results as applying to economies under uncertainty and to dynamic environments. General-equilibrium theory is a beautiful development and has long been a starting point for theoretical analysis of markets. Elegance comes at a cost. Shubik and Smith touch on many of the limitations of the general-equilibrium paradigm and describe ways to go beyond the framework. Describing the limitations provides an outline of the book's contributions.

General-equilibrium theory assumes that players are price takers. There are many situations in which individuals do have market power. There is now a well developed class of models that permit strategic behavior (Shubik and his co-authors created this literature). The book serves as an introduction (to those who need one) to the study of market games.

Game theory is the study of multi-player decision problems. A game consists of a set of players, a strategy set for each player, and payoff functions for each player. To go from a general-equilibrium description of a market to a market game, one must specify how the market institution works. One possibility is that each agent describes how much he or she is willing to trade (for each item, possibly as a function of price, time, or location) and a "black box" (or reduced-form model of market clearing) that determines which agents transact and the transaction prices on the basis of these reported trades. The realized trades determine the payoffs of agents. The fundamental difference between market games and general equilibrium is that in a market game economic agents take into account how their behavior influences the terms of trade while in general equilibrium agents assume their demand behavior does not influence prices.

It is problematic to include money in general-equilibrium models. The basic framework does not include the trading frictions that make it costly to have direct trades between all pairs of commodities. Even when one takes trading costs into account, there are significant conceptual issues surrounding which commodity (or commodities) will be honored in exchange and the conditions under which an item of no intrinsic value (a sheet of paper, a piece of plastic, a bitcoin) will be accepted as payment for goods that are directly useful. The book provides a coherent framework for the study of monetary exchange. The framework permits one to understand the factors that lead to an evolution from commodity money to fiat money and the institutions needed to support a monetary economy.

The problems that price-taking agents solve in general equilibrium are simple to describe: taking prices as given, they select consumption and production levels to maximize their utility or profit. Even assuming that agents know all of the parameters in these problems, the optimizations involve many variables and would be challenging to solve. ${ }^{1}$ These complications multiply when agents take into account the implications of their behavior on prices and make decisions at different points in time. Shubik and Smith take these complexities seriously. The book contains useful discussions of realistic goals to assume for goal-oriented agents (making the case that innovators may not be utility maximizers) and aim to construct models that are testable in laboratories.

One amazing feature of the theory of general equilibrium is that market equilibria, which nominally depend on decentralized decision making, are efficient. The invisible hand of the price system directs behavior towards non wasteful outcomes without help from any governance structures. In fact, institutions do exist. They are essential for providing public goods, but Shubik and Smith explore their value in building trust in money, reducing complexity, helping agents arrive at equilibria, and motivating innovation.

Shubik and Smith's book is not about air travel, but my flight/plight illustrates some places where generalequilibrium theory hides important details. In a basic general-equilibrium model, I wouldn't buy a plane ticket. Instead I would have a claim on services that depended on all possible contingencies. In theory, I would know 
in advance what would happen to me if the Washington-San Diego plane broke down. The richness needed for a complete contract is complicated beyond belief. ${ }^{2}$

General-equilibrium theory explains neither how I managed to purchase the ticket nor or the process that determined the price. Somehow the airline was willing to promise me a seat on the plane in exchange for my credit card information and a promise to honor certain conditions. There is a lot going on. The airline was confident that it would receive the equivalent of cash from my promises and also that it could later use the cash for something intrinsically valuable. I was confident (perhaps too confident) that there would be a seat on the airplane for me and the plane would fly as scheduled. Part comes from institutions that have the authority to support aspects of the contract. Part comes from informal mechanisms that operate over time. In addition to my credit card, the airline was aware of another currency - frequent flier miles - that indicated to them my loyalty and potential future value to the firm and, under certain conditions, I could use in lieu of money to exchange for airline services. Hence several of the featured elements of the book's treatise - complexity alternative media of exchange, dynamics, institutions, innovation, and strategic interaction - already arise in my simple story.

To go beyond general-equilibrium theory, Shubik and Smith build on essentially all of the main developments of economic theory over the past 65 years. They honor the 1950s growth models of Von Neumann and Gale. They invoke 1960s results that provide foundations for the intuition that price taking is a good approximation to strategic behavior in large markets. They use ideas from the development of non-cooperative games that were developed in the 1970s. They adapt their theories so that are can be tested using experimental methods that gained prominence in the 1980s. They appreciate, but take a nuanced and somewhat skeptical view, towards models of bounded rationality that are part of the recent boom in behavioral economics.

\section{From theory to applications}

General-equilibrium theory does not provide clear structure for someone interested in predicting or preventing financial crises. Surely the guidance that Shubik and Smith wish to explore could be relevant to stabilization policy. This book is work of theory, but the authors have advice for policy makers. ${ }^{3}$ At a high level, the lesson from the book is that theorists who wish to influence policy must open their black-box theories and explicitly include policy instruments. More practically, Shubik and Smith show how to construct toy models of "playable games" that are rich enough to permit interesting phenomena while simple enough to solve analytically, simulate, and test in laboratory settings.

\section{Economics and science}

The book points out connections between physics, biology, and chemistry. From physics, the main ideas are symmetry, dimension, and measurement. I would have liked to see a more formal discussion of these connections. Here are two examples. First, the authors propose that measurement is characterized by three properties: same operation independent of quantity, the ability to change units of measurement, and the ability to subdivide. These requirements suggest that measurement can be through of as a real-valued homogeneous function on a vector space that is invariant with respect to (at least) positive linear transformations. Although the authors apparently do not equate measurement with measure theory, but I am not confident that I have properly operationalized their definition. ${ }^{4}$ Second, the book mentions Gauge Symmetries in 4.4.2 but, even though the connection to market models is made explicit, the book only points out the formal similarity. It does illustrate how one can use formal similarity to get a deeper understanding of economic institutions.

The connection to biology and the guidance of markets is less formal. Here the authors point out some parallels between stability of organisms that must survive in an uncertain world to the central problems of their study. One aspect of this parallelism that could be developed is the balance between active governance of economic processes and the evolution of decentralized institutions that can regulate behavior. Analogies with evolution seem to be more closely associated with decentralized control rather than centralized guidance.

There is less emphasis on the relationship between the authors' approach and chemistry, but they make the useful connection between institutions and chemical catalysts in that they facilitate productive activities without being consumed. ${ }^{5}$ I would go further and say that some institutions are enhanced by their repeated use. A chemical catalyst facilitates a chemical reaction, but the catalyst returns to its initial condition upon completion of the chemical reaction. An economic institution may facilitate an economic transaction. When the transaction is complete, the institution will not only remain, but it may be stronger than it was before. People will have more trust in an institution that has performed well in the past. The added trust could lead more people 
to use the institution. Chemical catalysts are not enhanced by positive reputations, but economic institutions are.

\section{A missing link}

Laboratory experiments have become a standard tool for economists. The authors identify the two biggest values of the approach - experiments make it possible to test hypotheses of economic models in controlled settings and they provide a low-cost way to see how novel institutions or interventions function prior to introducing them to the natural economy. The success of experiments to test designs for auctions and school-choice mechanisms has received broad recognition and attention. The goals of Shubik and Smith's book are closely aligned to the broad objectives of mechanism design and recent emphasis on testing potential institutions.

\section{How to read the book}

The book avoids the dry theorem-proof exposition typical of mathematical economics. For the most part, the text provides verbal descriptions of formal models. The authors have given a lot of thought to technicalities, but they deliberately avoid making the most general statements to broaden their audience. This choice is consistent with their desire to provide models that would generate predictions that could be computed or simulated and tested in the laboratory. They provide formal models in the text and in appendices, but for the most part spare the readers of details. This was the right choice for exposition of the model, but it sometimes makes for challenging reading. The notation is consistent, but ever expanding and not intuitive. Because the paper does not systematically identify theorems, the reader does not get enough guidance about which results are the most important.

Chapter 5 based on the author's 2011 Journal of Mathematical Economics article "Endogenizing the provision of money: costs of commodity and fiat moneys in relation to the valuation of trade" (Smith \& Shubik, 2011). I view it as the theoretical center of the paper. Earlier chapters motivate and describe the basic framework and illustrate the authors' approach. Later chapters add to the models of Chapter 5, leading to what the authors call a "hyperastronomical explosion of special cases" developed in subsequent chapters. ${ }^{6}$ The explosion is a consequence of the ambition of the authors and the complexity of the general model. On one hand, they pose a large number of interesting questions. On the other hand, it is not possible to arrive at answers to all of the questions at the same time. Their approach, keeping with a broader tradition, is to push the analysis of different special cases as far as possible. Chapter 5 compares the operation of a dynamic market game with commodity monetary system (gold) and fiat money. Fiat money is an artificial commodity used to pay administrative salaries, which are in turn funded through taxation. Provided that administrators do their job (essentially by supporting the value of money by enforcing contracts), agents will use it in equilibrium to eliminate intertemporal trading frictions.

One must be impressed with the breadth of knowledge the authors display. The work directly invokes results, ideas, and methods from other scientific disciplines. The authors place their contribution in context, displaying encyclopedic knowledge of the development of the basic ideas from economic theory. The text contains many asides and short subsections that point towards the broader relevance of the book's ideas. The footnotes contain sharp and sometimes amusing asides on topics ranging from political philosophy to Greek mythology. I felt like I was in the company of wise, generous, but somewhat undisciplined dinner hosts, who prepared more than enough of their favorite dishes, and happily share details about the ingredients and preparation. I reacted like a dazzled guest. I was happy to be invited to the feast, but unable to savor individual dishes and sometimes anxious to push away from the table. My recommendation to a potential reader is to read the book selectively, picking out attractive segments rather than moving through the book linearly.

\section{Acknowledgement:}

We mourn the loss of Martin Shubik (1926 - 2018), a gifted scholar and a dear friend. Through his remarkable ideas and insights, Shubik helped founding and shaping the CONVIVIUM with his guidance, advice, and inaugural contribution "Accounting and Economic Theory: Past, Present, and Future" (DOI: https://doi.org/10.2202/2152-2820.1012). At the time of his passing on August 22, 2018, editorial work on this symposium on his last book with Eric Smith, The Guidance of an Enterprise Economy, has been underway. It 
is now published to honour him and his outstanding contributions to economics, management science, game theory, and accounting scholarship.

\section{Funding}

This work was supported by Directorate for Social, Behavioral and Economic Sciences, Funder Id: 10.13039/100000088, Grant Number: 1326376.

\section{Notes}

1 Another issue is that these problems may have many solutions, but equilibrium typically requires that the decision maker chose in a specific way when indifferent. Hence equilibrium theory gives no insight into how one arrives at equilibrium.

2 This does not mean that real life is simple. The airlines do not simply sell tickets on a particular flight. The commodity changes depending on where you sit on the plane, how many bags you check, and even when you purchase the ticket.

3 I could find only one explicit policy proposal. In Section 13.10, the authors describe a Federal Employment Reserve Agency. FERA would be an independent federal agency charged with stabilization the employment level in the same way that the Federal Reserve currently works to stabilize the rate of inflation. The brief discussion acknowledges that any such institution would be imperfect.

4 In contrast, the book contains careful and insightful discussions of the importance of time scale in their analyses.

5 As the authors point out, the formal connection between the input-output matrices of linear growth models and stoichiometric matrices makes this more than a good analogy.

6 The development calls to mind Italo Calvino's Mr. Palomar who "needed a great variety of models, whose elements could be combined in order to arrive at the one that would best fit reality, a reality that, for its own part, was always made up of many different realities, in time and in space." (Calvino, 1985).

\section{References}

Calvino, I. (1985). Mr. Palomar. San Diego: Harcourt Brace Jovanovich.

Smith, E. \& Shubik, M. (2011). Endogenizing the provision of money: Costs of commodity and fiat monies in relation to the value of trade. Journal of Mathematical Economics, 47(4-5), 508-530. 